\title{
Remote and Local Influences in Forecasting Pacific SST: a Linear Inverse
} Model and a Multimodel Ensemble Study

Daniela Faggiani Dias* and Aneesh Subramanian

Scripps Institution of Oceanography, UCSD

Laure Zanna

University of Oxford, Oxford, UK

Arthur J. Miller

Scripps Institution of Oceanography, UCSD

${ }_{9}^{*}$ Corresponding author address: Daniela Faggiani Dias, Scripps Institution of Oceanography, 10 UCSD.

11 E-mail: dfaggian@ucsd.edu 


\section{ABSTRACT}

12 A suite of statistical linear inverse models (LIMs) are used to understand ${ }_{13}$ the remote and local SST variability that influences SST predictions over the ${ }_{14}$ North Pacific region. Observed monthly SST anomalies in the Pacific are 15 used to construct different regional LIMs for seasonal to decadal prediction. ${ }_{16}$ The seasonal forecast skills of the LIMs are compared to that from three 17 operational forecast systems in the North American Multi-Model Ensemble ${ }_{18}$ (NMME) revealing that the LIM has better skill in the Northeastern Pacific than NMME models. The LIM is also found to have comparable forecast ${ }_{20}$ skill for SST in the Tropical Pacific with NMME models. This skill, however, is highly dependent on the initialization month, with forecasts initial${ }_{22}$ ized during the summer having better skill than those initialized during the ${ }_{23}$ winter. The data are also bandpass filtered into seasonal, interannual and ${ }_{24}$ decadal time scales to identify the relationships between time scales using ${ }_{25}$ the structure of the propagator matrix. Moreover, we investigate the influence ${ }_{26}$ of the tropics and extra-tropics in the predictability of the SST over the region. ${ }_{27}$ The extratropical North Pacific seems to be a source of predictability for the 


\section{Introduction}

The Pacific Ocean sea surface temperature (SST) exhibits variability on timescales from diurnal (Tanahashi et al. 2003; Clayson and Weitlich 2007) to decadal and centennial timescales (Mantua et al. 1997; Power et al. 1999; Yeh et al. 2011). These coherent large-scale SST anomalies observed in the Pacific Ocean also impact the weather and climate in regions around the Pacific and globally (e.g., Vimont et al. 2001; Grimm and Tedeschi 2009; Allen et al. 2015; Capotondi and Sardeshmukh 2015; L'Heureux et al. 2015). SST fluctuations over the Pacific Ocean are caused by various mechanisms, both internal ocean variability as well as local and remote stochastic atmospheric heat and momentum flux forcings (Bjerknes 1966; Battisti and Hirst 1989; Newman et al. 2016). Some of the processes that influence the SST anomaly evolution over this region involve stochastic atmospheric forcing with damped oscillatory modes in the ocean surface, coupled ocean-atmosphere damped oscillatory modes with random forcing as well as modes of internal variability (Frankignoul and Hasselmann 1977; Penland and Matrosova 1994; Di Lorenzo et al. 2015).

For more than a century scientists have been exploring factors that impact the SST evolution over the North Pacific region and especially over the California Coastal region. McEwen (1914) explored impacts of temperature difference between the continent and the ocean on the large-scale atmospheric pressure and circulation over the Pacific, which then impacts the SST and leads to a feedback on the process on decadal timescales (Newman et al. 2016). Therefore, it is important to investigate not only which modes of variability in the Pacific dominate each timescale, but also the interactions among those scales of variability, in order to improve our understanding of the role of such interaction in the predictability.

For seasonal to interannual time scales, the El Niño Southern Oscillation (ENSO) is the dominant 
source of variability for the Pacific Ocean and it has been identified as the highest source of predictability in these time scales for SST anomalies in the tropical Pacific (Xue et al. 2013). The predictability of ENSO variability has been tested using several statistical and physical methods, ranging from linear methods (e.g., Linear Inverse Models, Penland, 1989; Penland and Sardeshmukh, 1995, and canonical correlation analysis, Barnston and Ropelewski, 1992), nonlinear statistical methods (e.g., Eccles and Tziperman 2004; MacMynowski and Tziperman 2008; Chen et al. 2016) to operational coupled general circulation models (e.g., North-American Multimodel Esemble - NMME, Kirtman et al. 2014). The later is a global prediction system that was recently developed to exploit the idea of using multiple models to improve the skill of the forecasts. Indeed, Becker et al. (2014) showed that NMME mean forecasts have more skill in predicting ENSO-related variability than individual models.

The decadal variability in the Pacific is also well known, but the mechanism that control these longterm variations are still unclear. The Pacific Decadal Oscillation (PDO; Mantua et al. 1997) represents the primary mode of SST variability across the midlatitude North Pacific. Although PDO is correlated with a number of physical and biogeochemical variables, its dynamical mechanism is associated with the combination of a few phenomena (Miller and Schneider 2000; Schneider and Cornuelle 2005; Newman et al. 2016): teleconnections from the tropical Pacific via "atmospheric bridges" (Alexander et al. 2002), large-scale stochastic atmospheric forcing via intrinsic variability of the Aleutian Low, ocean memory via reemergence mechanism (Alexander and Deser 1995), and Rossby wave signatures along the Kuroshio-Oyashio Extension (KOE) region (Qiu 2003; Taguchi et al. 2007). Moreover, the decadal variability in the Pacific is not dominated by PDO to the same degree as the interannual variability is dominated by ENSO (Newman 2013), and other modes do play a role. The North Pacific Gyre Oscillation (NPGO; Di Lorenzo et al. 2008) represents the second mode of North Pacific SST and it characterizes the oceanic response to the atmospheric 
pressure pattern called North Pacific Oscillation (NPO; Linkin and Nigam 2008; Ceballos et al. 2009).

The ability to predict these fluctuations of Pacific SST anomalies has many obvious economical and societal benefits because it can help improve adaptation and mitigation to extreme weather and climate anomalies (Alexander et al. 2008). Yet, current generation of numerical models have many limitations in predicting the system accurately in this region (Meehl et al. 2014; Becker et al. 2016; Barnston et al. 2017; Newman and Sardeshmukh 2017) and the long record of observations can be used to help inform the models better. Our goal in this study is to understand the remote and local SST variability that influences SST predictions over the North Pacific region and to investigate the interactions between dominant modes of variability on time scales from seasonal to decadal. With that, we expect to improve our understanding on how the long observed SST record can help better guide multi-model ensemble forecasts.

We use a linear inverse model (LIM, Penland and Magorian 1993) to estimate the predictability of the SST anomalies in the North and Tropical Pacific at different time scales. We then use a suite of the seasonal forecasts from NMME models to investigate the limits on forecast skill of the system, by comparing a low-dimensional empirical linear model with a high-dimensional nonlinear coupled model. LIM constitutes the least complex form of a reduced stochastic-dynamic climate model (Majda et al. 2009) and it has been broadly used for diagnostic and prediction of tropical and extratropical weather and climate from diurnal to decadal time scales (Penland and Sardeshmukh 1995; Alexander et al. 2008; Newman et al. 2009; Zanna 2012; Cavanaugh et al. 2014; Capotondi and Sardeshmukh 2015; Huddart et al. 2016; Newman and Sardeshmukh 2017). Those studies have shown that LIMs have comparable predictive skill to high-dimensional global circulation models, despite their reduced number of degrees of freedom.

This paper is organized as follows. In Section 2 we briefly introduce the LIM theory. Section 3 de- 
scribes the data used and establishes the LIM model configuration and the experiments performed.

Section 4 shows LIM forecasts skills for seasonal, interannual and decadal experiments as well as shows the comparison with NMME hindcasts skill. Finally, in Section 5 we summarize the main results and point some concluding remarks.

\section{Linear Inverse Modeling}

Linear Inverse Model (LIM) assumes that the evolution of some phenomena in a system can be represented as a linear process forced by stochastic noise. In other words, it can be separated into a linear deterministic part and a nonlinear part, represented by white noise fluctuation, which may be spatially correlated but temporally uncorrelated. Therefore, the governing dynamics of such system can be represented in the form:

$$
\frac{d \boldsymbol{x}}{d t}=\boldsymbol{L} \boldsymbol{x}+\boldsymbol{\xi}
$$

where $\boldsymbol{x}$ is the system state vector, $\boldsymbol{L}$ is the time-independent linear operator matrix and $\boldsymbol{\xi}$ is the white stochastic forcing. A detailed description of LIM procedure have been broadly discussed in several papers (e.g., Newman et al. 2003; Newman 2007; Penland and Sardeshmukh 1995), so here we only provide some essential information necessary for discussion.

The linear operator $\boldsymbol{L}$ can be estimated from the observed statistics of the system under consideration if the relation in (1) is stable. For that, we use the lag covariance matrix $C(\tau)$ of the system with components $\boldsymbol{x}_{i}$, estimated at any fixed lag $\tau$ from the observations as $C_{i j}(\tau)=$ $\left\langle\boldsymbol{x}_{i}(t+\tau) \boldsymbol{x}_{j}(t)\right\rangle$, where the angle brackets denote a long-term average and the subscripts $i$ and $j$ represent the covarying observational time-series. Given that in linear inverse modeling one assumes that the relation in (1) is valid, the system satisfies the relation 


$$
C(\tau)=B(\tau) C(0)
$$

where $\boldsymbol{C}(0)$ is the lag 0 covariance matrix of the state vector $\boldsymbol{x}$ and $\boldsymbol{B}(\tau)=\exp (\boldsymbol{L} \tau)$ is the propagator matrix that represents the decaying of the predictable signals at some lead time $\tau$. Finally, for some chosen lag-time $\tau_{0}$, the matrices $\boldsymbol{L}\left(\tau_{0}\right)$ and $\boldsymbol{B}(\tau)$ can be determined from the estimates of $\boldsymbol{C}\left(\tau_{0}\right)$ and $\boldsymbol{C}(0)$ as follows:

$$
\boldsymbol{B}(\tau)=\exp (\boldsymbol{L} \tau)=\left[\boldsymbol{C}\left(\tau_{0}\right) \boldsymbol{C}(0)^{-1}\right]^{\frac{\tau}{\tau_{0}}}
$$

The matrices $\boldsymbol{L}$ and $\boldsymbol{B}$ should be independent of the choice of $\tau_{0}$ and how well this holds can be used as a measure of the efficacy of applying LIM to the system (Penland and Sardeshmukh 1995).

Given the estimation of the deterministic part of the system using LIM, the forecast of $\boldsymbol{x}(t+\tau)$ can be made by analytically solving (1), which results in

$$
\boldsymbol{x}(t+\tau)=\boldsymbol{B}(\tau) \boldsymbol{x}(t)
$$

where $\tau$ is the lead time, $t$ is the initial condition and $\boldsymbol{B}(\tau) \boldsymbol{x}(t)$ will be the best forecast in the least square sense.

\section{Model details and experiments}

\subsection{Data}

The SST dataset used for the LIM analysis and forecasts are from the Hadley Center Sea Ice and Sea Surface Temperature (HadISST, Rayner et al. 2003), interpolated on a $1^{\circ}$ by $1^{\circ}$ grid for the North and Tropical Pacific (between $15^{\circ} \mathrm{S}$ to $60^{\circ} \mathrm{N}$ ), and with monthly means from 1900 to 2016. 
The normalized anomalies (SSTa) are determined by first removing the climatological monthly mean for each grid cell at each month, then dividing by their standard deviation and finally weighting each grid cell by their surface area, in order to equally weight the tropical and subtropical one degree cells. SSTa are filtered with a third order Butterworth filter for three different time scales: decadal (D), with periods greater than 10 years; interannual (I), with periods between 1 and 10 years; and seasonal $(\mathrm{S})$, with periods less than 1 year.

Singular value decomposition (SVD) is applied for the unfiltered SSTa time series (U) and for each of those three filtered datasets separately (D, I and S). Therefore, the SSTa fields are decomposed into empirical orthogonal functions (EOFs) that describe the spatial pattern, and their associated principal components (PCs) that describe the time evolution. In addition to temporal fields, PCs and EOFs are also determined for different spatial fields over the Pacific: tropics plus extratropics (PA, $15^{\circ} \mathrm{S}$ to $60^{\circ} \mathrm{N}$ ), only tropics (TP, $15^{\circ} \mathrm{N}$ to $15^{\circ} \mathrm{S}$ ), and only extratropics $\left(\mathrm{ET}, 16^{\circ} \mathrm{N}\right.$ to $60^{\circ} \mathrm{N}$ ).

\subsection{LIM configuration}

We choose to construct the SSTa state vector as a truncated time series of the leading PCs, and the form of $\boldsymbol{x}$ depends on which experiment is being performed, either unfiltered (for seasonal forecasts), or filtered SSTa (for interannual and decadal forecasts).

\subsection{1) UNFILTERED LIM}

For the unfiltered experiments, the state vector $\boldsymbol{x}$ is built using the leading 20 PCs of SSTa $\left(\boldsymbol{x}_{U}\right)$. Moreover, one state vector is built for each spatial field $\left(\boldsymbol{x}_{U P A}, \boldsymbol{x}_{U T P}\right.$ and $\left.\boldsymbol{x}_{U E T}\right)$. Therefore, Eq. (1) can be rewritten for the unfiltered experiments as: 


$$
\begin{gathered}
\frac{d \boldsymbol{x}_{U P A}}{d t}=\boldsymbol{L}_{U P A} \boldsymbol{x}_{U P A}+\boldsymbol{\xi}_{U P A} \\
\frac{d \boldsymbol{x}_{U T P}}{d t}=\boldsymbol{L}_{U T P} \boldsymbol{x}_{U T P}+\boldsymbol{\xi}_{U T P} \\
\frac{d \boldsymbol{x}_{U E T}}{d t}=\boldsymbol{L}_{U E T} \boldsymbol{x}_{U E T}+\boldsymbol{\xi}_{U E T}
\end{gathered}
$$

\subsection{2) FILTERED LIM}

To construct the state vector $\boldsymbol{x}$ for the filtered experiments, we follow the methodology adopted in Huddart et al. (2016). We use the leading 20 PCs corresponding to each time scale $\left(x_{D}, x_{I}\right.$ and $x_{S}$ ), and put them together as a single 60-component vector. As in the unfiltered experiment (Section 3.3.23.2.1), one state vector is built for each spatial field $\left(x_{P A}, x_{T P}\right.$ and $\left.x_{E T}\right)$. So, the vectors $\boldsymbol{x}$ for the filtered experiments have the following form:

$$
x_{P A}=\left[\begin{array}{c}
x_{D P A} \\
x_{I P A} \\
x_{S P A}
\end{array}\right] \quad x_{T P}=\left[\begin{array}{c}
x_{D T P} \\
x_{I T P} \\
x_{S T P}
\end{array}\right] \quad x_{E T}=\left[\begin{array}{c}
x_{D E T} \\
x_{I E T} \\
x_{S E T}
\end{array}\right]
$$

With this definition of $\boldsymbol{x}$, we can rewrite Eq. (1) in a general form as:

$$
\frac{d}{d t}\left[\begin{array}{c}
x_{D} \\
x_{I} \\
x_{S}
\end{array}\right]=\left[\begin{array}{ccc}
\boldsymbol{L}_{D D} & \boldsymbol{L}_{D I} & \boldsymbol{L}_{D S} \\
\boldsymbol{L}_{I D} & \boldsymbol{L}_{I I} & \boldsymbol{L}_{I S} \\
\boldsymbol{L}_{S D} & \boldsymbol{L}_{S I} & \boldsymbol{L}_{S S}
\end{array}\right]\left[\begin{array}{c}
x_{D} \\
x_{I} \\
x_{S}
\end{array}\right]+\left[\begin{array}{c}
\xi_{D} \\
\xi_{I} \\
\xi_{S}
\end{array}\right]
$$

We can observe in Eq. (9) that it is possible to diagnose linear relationships among the different time scales through the dynamical operator $\boldsymbol{L}$. Its diagonal components represent the interaction 
between each time scale with itself, while the off-diagonal components diagnose the interactions between two time scales. Filtering the data allows us to investigate how each time scale interacts with one another at different lead times, as well as the direction of this interaction (e.g $\boldsymbol{L}_{D I}$ represents the downscale interactions, hence how decadal modes drive interannual modes).

\subsection{LIM forecasts}

Following the procedure described in section 2 , we use the propagator matrix $\boldsymbol{B}$, to do the forecasts of the PCs time series. First we do forecasts on seasonal time scale using the unfiltered SSTa time series for each spatial field, hence using the state vectors from Eqs. 5, 6 and 7.

The forecast made are 12-month long and they are initialized every month from January to December of the years 1995 to 2010 (experiments PA95, TP95 and ET95). The estimates of $\boldsymbol{B}$ and the forecast skill are made in a cross-validation sense by first excluding those 15 years of the SSTa time series (which we call here as verification period), and estimating $\boldsymbol{B}$ for the remainder years. The 12-months forecasts are then generated for every month of the independent 15 years, resulting in a total of 180 seasonal forecasts. In order to test the influence of the excluded data on the predictability, we used a different verification period to perform this LIM 12-months forecast (from 1950 to 1965, experiments PA50, TP50 and ET50).

The LIM's seasonal forecast skill is then compared to that of the models of the North American Multimmodel Ensemble (NMME, Kirtman et al. 2014). The models included are all the GCMs from NMME phase 1 that have monthly SST hidcasts: the Community Earth System Model (CESM1) and the Canadian Center for Climate Modeling and Analysis (CanCM3 and CanCM4). NMME dataset can be found in http://iridl.ldeo.columbia.edu/SOURCES/.Models/.NMME/. The NMME hindcasts are also 12-month long and are initialized every month from January to December of the years 1995 to 2010 . We used the ensemble mean of those models and calculated 
the anomalies by subtracting the climatological mean of each month and each lead time of the hindcast.

To evaluate the forecast skill and the predictability, we use two measures: the anomaly correlation coefficient (ACC) and the root mean square error (RMSE). Those estimates are calculated by comparing LIM and NMME forecasts with the HadISST data. First we calculate the ACC for each grid cell at different lead times for the LIM forecasts (experiments PA50, TP50, ET50 and PA95, TP95, ET95). This test allows us to quantify the skill at a given lead time and at different parts of the domain. Therefore, we can estimate in which areas of the domain the SSTa evolution is well approximated by linear dynamics. Moreover, forecasting the SSTa field separately for TP and ET allows us to compare the skill with the forecast made including those two regions (PA). With that, we aim to diagnose whether the Tropical variability increases the skill to forecast the Extratropical variability and vice-versa.

We then choose two regions in the Pacific to perform the LIM and NMME comparison: California Current System $\left(\mathrm{CCS}, 30^{\circ} \mathrm{N}\right.$ to $40^{\circ} \mathrm{N}$ and $232^{\circ} \mathrm{E}$ to $\left.244^{\circ} \mathrm{E}\right)$ and Niño 3.4 region $\left(5^{\circ} \mathrm{S}\right.$ to $5^{\circ} \mathrm{N}$ and $190^{\circ} \mathrm{E}$ to $240^{\circ} \mathrm{E}$ ). We calculated the SSTa spatial mean within those regions for each of those datasets and the skill was evaluated by calculating the ACC between each forecast and the observations, for each lead time and each start month. Aditionally, we computed the time evolution of RMSE between each forecast and observations, for each region.

Finally we do forecasts individually for the interannual and the decadal components, for each spatial field using the state vectors $(\boldsymbol{x})$ described in Eq. 8. Although the forecast is made individually for each time scale, the interactions among $\boldsymbol{x}_{D}, \boldsymbol{x}_{I}$ and $\boldsymbol{x}_{S}$ are explicitly included in $\boldsymbol{B}$. Therefore, the forecasts made for each individual time scale takes into account the linear relationship between each other.

The forecast skill calculations are also cross-validated and evaluated by using the maps of ACC. 
For this case, LIM-forecasts are 10-years long and they are also initialized every month from January to December of the years 1950-1960. We remove the 10 years of the SSTa time series, then we calculate the EOFs and PCs for the remainder years and we use those to estimate $\boldsymbol{B}$. The forecasts are then made for the independent 10 years removed and this procedure is repeated for each month along those 10 years, resulting in a total of 120 forecasts.

\section{Results and discussion}

\subsection{Seasonal forecasts: unfiltered data}

The predictability of North and Tropical Pacific SSTa was first evaluated using the ACC for the unfiltered data on a seasonal time scale. Figures 1 and 2 show the ACC for 3, 6, 9 and 12 forecast lead months for all the experiments described in Section 3.2.1 (50 and 95, respectively).

Overall, the spatial distribution of the forecast skill for all the experiments are very similar, with higher skill seen in three key regions, marked in the Figure 1a with a black circle and with the numbers 1 to 3: a circular-shaped region in the northwestern Pacific (1), a broad region along the coast of North America extending southwestward to the central Pacific (2), and a region east of the dateline in the border of the South tropics (3). Skill minima are found in the equatorial cold tongue region in the eastern Pacific, in regions surrounding the circular shaped region of maximum skill in the northern extra-tropics, and in a V-shaped region in the western Pacific. The decrease in skill with the increasing lead time is also similar for all the experiments. Not surprisingly, the regions of little skill are located along the regions of the higher amplitude of the first and second EOF modes of the Pacific. Those areas have the weakest forecast signal for a linear model, probably because either stochastic or non linear processes dominate the variability. On the other hand, re- 
gions with the highest forecast skill are likely associated with ENSO or PDO related signals where SSTa evolution is largely driven by slower timescale processes which tend to be more linear. Excluding data from the tropics or the extratropics to make the forecast and comparing their skill with the forecast made with the whole domain allowed us to identify regions with high variability modes. Including the extra-tropical SST field in the forecast model helps improve the skill in predicting the tropical SSTs (experiments P50 and P95 compared to TP50 and TP95). By comparing Figures 1a-d and 2a-d to 1e-h and 2e-h, it is possible to identify a loss in skill for TP50 and TP95 experiments right in the first 3 months of forecast, which is an indication of a forcing, where the extratropics are a source of predictability for the tropics. This is consistent with several studies performed over the past two decades, that have identified the mechanism behind this forcing mechanism. The atmospheric variability of the North Pacific have been identified as a forcing for the tropical climate variability through the North Pacific Oscillation (NPO) and through the excitement of the Pacific Meridional Mode (PMM) (e.g., Vimont et al. 2001, 2003, 2009; Chiang and Vimont 2004; Chang et al. 2007; Di Lorenzo et al. 2015). During boreal winter, the southern branch of NPO modulates the strength of the northeasterly trade winds, leaving an anomalous imprint in the SST through latent heat flux changes. Those anomalies persist into boreal summer and induce changes in the Tropical atmospheric circulation. This is the so-called Seasonal Footprint Mechanism (SFM) (Vimont et al. 2003). Additionally, the PMM have been identified as precursor for El Niño events, acting as a conduit through which the extratropical atmospheric variability is conducted to the tropics (Chiang and Vimont 2004; Chang et al. 2007; Vimont et al. 2009). Despite the fact that our analysis included only SST data, LIM implicitly includes the impact of all other variables that are related to SST (Newman 2007). Moreover, the persistence of high skill forecast up to 12 months in the region (2) in Figure 1a resembles the shape of PMM. Therefore, the linear model captured the effect of atmospheric extratropical variability on the tropical climate 
and the forecast skill improvement is an indication that the SST evolution as well as the interactions with the atmosphere are well approximated by linear dynamics. A recent study suggested that the influence of the midlatitudes SST anomalies associated with NPO and the propagation into the tropics through the PMM is essentially linear (Thomas and Vimont 2016). Our results support this suggestion and add one more evidence for the linearity of this mechanism.

Considerations on the spatial characteristics of ENSO can be made with our results. The SST anomalies are well approximated with the LIM in the central tropics, with ACC greater than 0.4 persisting until one year of forecast. On the other hand, the skill in the eastern tropics decreases much faster, with ACC close to zero after six months of forecast (Figure 1a-h and 2a-h). The geographical distribution of skill in the tropics resembles the two types of ENSO that are known: the Central-Pacific $(\mathrm{CP})$, which produces warm SST anomalies in the tropics around the dateline, and the Eastern-Pacific (EP), where the warm SST anomalies are spread from the eastern tropics to the dateline. The precursors that influence the development of each type of ENSO have been recently investigated. The PMM has been suggested to play a key role in the development of CP ENSO events (Alexander et al. 2010; Yu and Kim 2011; Kim and Yu 2012; Vimont et al. 2014; Thomas and Vimont 2016), although there is no agreement in the literature that it is the main cause. An additional explanation explores the influence of the initial thermocline state in the selection of a specific type of ENSO, in which a deeper thermocline in the eastern (central) tropics favors a EP (CP) ENSO events (Capotondi and Sardeshmukh 2015). The LIM results suggest that the central tropics SST anomalies are more influenced by linear processes than the anomalies in the eastern tropics. Thomas and Vimont (2016) proposed that the thermocline parameters are strongly dependent on the nonlinear dynamics while PMM influence is mostly linear. Therefore, our results are consistent with those findings and they highlight the importance of different contributors to the predictability in the Tropical Pacific. 
Regarding the forecast for the extratropics, the tropics either do not improve the skill (experiment PA50, Figures 1a-d) or act to worsen it for mostly North Pacific (experiment P95, Figures 2a-d). For example, in PA95 the ACC decreases to 0.2 after 12 months of forecast, while it remains higher than 0.6 when the tropics are excluded (ET95). Curiously, it is known that the variability in the tropical region, especially ENSO, influence the evolution of SST anomalies in the North Pacific, through atmospheric bridges (e.g., Alexander et al. 2002). Furthermore, those atmospheric bridges contribute to the SST variability on time scales longer than interannual (Zhang et al. 1997) and they are known to be one of the contributors for the development of PDO (Newman et al. 2016). For this reason, one would expect that including information from the tropics would increase the predictability for the North Pacific, which was not the case for our results. However, the tropical forcing that contributes to the evolution of North Pacific SST is the low-frequency variability, and those results include the high-frequency data and were focused on seasonal forecast. Bearing that in mind, we explore the predictability with filtered data to evaluate the temporal interactions in improving the predictability for SST, and we present and discuss the results in Section 4.4.2.

Despite the general similarities of the skill for the experiments using two different verification periods, there are some outstanding differences between them, especially for the experiments TP50 and TP95. There is a clear loss in skill for longer lead times when forecasting the SST evolution between 1995 and 2010. A detailed explanation of the reasons behind this loss in skill is beyond the scope of this paper. However, these results are presented to show that similar models can have different results according to the data used to train the model. For example, in the period between 1995 and 2010 there was a major El Niño event (1997/1998), whose information probably would dominate the oscillatory pattern of the SSTa evolution, thereby adding predictability to the linear model. As this information was lost when cross validating, this could help to decrease the skill. Additionally, the background climate can act to decrease the predictability for certain 
periods (Zhao et al. 2016). The 1995 to 2010 period corresponds to a change in the background climate, represented by a transition between the positive (1977 - 1999) and the negative (1999 2010) phases of the Interdecadal Pacific Oscillation (IPO), while the years between 1950 and 1970 correspond entirely to the negative phase of the IPO (Henley et al. 2015).

In the next subsection we present the comparison between LIM and NMME models and present a more detailed discussion about the limits of predictability as well as remote influences in some key regions for the Pacific SST.

\subsection{1) NMME AND LIM COMPARISON}

In order to compare the predictability achieved by a simple LIM with a more complex GCM, the results of LIM experiments are contrasted with the NMME hindcasts by comparing their ACC and RMSE for different initialization times. Figures 3 and 5 show the correlations as a matrices with initialization month on the x-axis and lead time on the y-axis, for the regions Niño 3.4 and CCS, respectively. Figures 4 and 6 show the RMSE evaluated for each NMME model and the LIM experiment that were initialized for austral winter (December, January and February) and summer (June, July and August). This approach allows us to study if the SST forecast skill in the region changes with different forecast periods, and also the linearity assumption for the SST dynamics during different periods.

The forecasts are highly sensitive to initialization months for the Niño 3.4 region and this difference is more dramatic for the LIM forecast during late twentieth/early twenty-first centuries (PA95 and TP95) (Figure 3). Overall, the forecasts initialized during austral late spring and summer (from May to September) tend to have higher skill that persists for longer lead times. On the other hand, forecasts initialized before austral spring (January to April) are much less successful, with high skill persisting for no longer than four months. Other studies have also seen 
this lack in forecast skill for ENSO forecasts initialized before spring of the El Niño year and this is known as the "Spring Predictability Barrier" (SPB) for ENSO (Webster and Yang 1992; McPhaden 2003; Jin et al. 2008; Duan and Wei 2013; Lopez and Kirtman 2014). Another similar characteristic for those matrices is that they exhibit a higher skill along their diagonal. This occurs when the month that is being predicted has more skill independently of the lead time, which tend to arise when the skill is a result of impacts that depend on the season (Hervieux et al. 2017). Despite those general similarities, there is a striking difference between NMME skill and LIM skill when initializing the forecast in the austral winter. The SPB appears much more evidently in the LIM experiments (particularly PA95 and NP95), where the skill abruptly decreases after a certain lead time. For NMME models, the SPB is there, though the decrease in the skill is more smooth, with positive skill persisting up to 12 months. By comparing two essentially different forecast systems, LIM, which is an empirical linear model, and the NMME models, which are high dimensional nonlinear coupled models, some considerations can be made about the predictability of the nonlinear signals. As stated before, LIM assumes that the nonlinear part of the signal is unpredictable, so the skill comes basically from the linear part. The similarity of NMME skill and LIM skill for the forecasts initialized during austral late spring and summer can be an indication that the nonlinear signals for the following months are essentially unpredictable. On the other hand, when initialized during austral winter, the remarkable differences after the 4th month of forecast are a hint for the more predictable nonlinear signals, and possibly with some room for improvement of the LIM by adding additional stochastic noise to the system (e.g., Majda et al. 1999).

Interestingly, there is a big difference in the skill of the forecast for different periods. Although the forecast initialized during austral late spring and summer have higher skill persisting up to 8 months, the SPB is much less clear for experiments PA50 and TP50. For example, for the 
TP50, there is positive skill up to 12 months for experiments initialized before June. Beyond the SPB, although, PA95 and TP95 perform better. A plausible explanation for those differences can be the occurrence of major El Niño events on the period that is being predicted, which can enhance the SPB. In the case of PA95 and T95, a major El Niño event has occurred (1997/98). On the contrary, during the period of PA50 and TP50 experiments, there was very weak El Niño interannual variability.

Those differences can be further explored using the evolution of RMSE with lead time for each NMME model and for each LIM experiment, with initialization during winter and summer months (Figure 4). For the initialization during the winter, the RMSE of the LIM and NMME models forecasts are not significantly different until 5 months of lead time. The exception is to the CESM1 model, that performs slightly worse than all the others. From six months of forecast onwards, the RMSE for the LIM experiment TP95 starts to grow fast, while the RMSE for the other models are still comparable. On the other hand, for experiments initialized during summer months, the differences between the RMSE of the models are much bigger: LIM experiment PA95 performs better than any other model up to 8 months, while PA50 and TP50 have comparable RMSE with NMME models. Curiously, when excluding the North Pacific for the verification period of 1995 - 2010, the error grows faster already in the second lead month, and in the third lead month it has larger errors than any other model. Those results reinforce our earlier discussion that the North Pacific is a source of predictability for the Tropical region, especially when forecasting for the late twenty/early twenty-first centuries.

When considering the CCS region, the LIM forecasts have, overall, better skill than the NMME models (Figure 5). LIM and NMME forecasts, although, demonstrate good skill across nearly all initialization months up to six months of lead time (the exception is for CESM1 experiments initialized during austral late fall and winter). The matrices present the high skill diagonal pattern, 
as for Figure 3. For example, enhanced predictability is found when forecasting for late fall (October/November) and, less evident, for the early spring (February - April), which can be seen as two bands of high skill extending from the lower right to the upper left (exception again is for the CESM1 model). When the experiment is initialized during austral winter months, LIM and NMME have similar skill and nearly no significant difference in the RMSE up to six months of lead time (Figure 6). The exception is for the CESM1 model, that presents the lowest skill and the biggest RMSE between all the models and experiments. Including the tropics (PA) or no (ET) in the analysis do not influence in the forecast, with the results being very similar when considering same verification period. However, for the forecasts initialized during the summer, the differences are more significant: in general, LIM experiments perform better than the NMME models, in particular for the ones using the verification period of 1995 - 2010. Moreover, including the tropics to train the LIM (PA95) makes that the RMSE is the lowest for almost all lead times. In opposition, the forecast made for 1950 - 1965 without the tropics (ET50) has a smaller RMSE than the one including the tropics (PA50). These results suggest that the Tropical variability can be a source of predictability for the CCS, depending on the period that is being considered. Specifically, the ENSO-related variability might add some seasonal predictability for the CCS, since in period with major ENSO variability (1995 - 2010) there is a decrease in the RMSE when including information from the tropics; on the other hand, in a period with less ENSO variability (1950 - 1965), local variability seems to play a more important role on the predictability, what can be seen by the decease in the RMSE when excluding the tropics. Indeed, in a recent study, Jacox et al. (2015) found that the skill above the persistence for the CCS derives primarily from predictable evolution of ENSO related variability, where the mechanism prevails during years with moderate to strong ENSO events. 


\subsection{Interannual and decadal forecasts}

The predictability of the interannual and decadal components of SSTa in the North and Tropical Pacific Ocean is explored using a filtered field of SST to build the LIM, as explained in Section 33.1. The EOFs field for the decadal, interannual and intraanual components, which the correspondent PCs were used to build the propagator matrix, are presented in Figure 7. Not surprisingly, the well-known PDO pattern dominates the variability for the decadal component and ENSO dominates the variability for the interannual time scales.

The ACC maps for the forecast of the interannual component is presented in Figure 8. Although the highest skill regions up to six months are similar to those presented for the seasonal unfiltered forecast, the values of the ACC are smaller, with a maximum skill of 0.6 in those regions (against 0.8 in the unfiltered experiments). The extratropical forcing to the tropics can also be identified for the interannual experiments by comparing Figures $8 \mathrm{a}$ with 8e: there is a clear loss in the skill for the tropics for the TP experiment, where the ACC has a typical value of 0.2 . After one year of forecast, the skill is almost completely lost, with zero or negative values for mostly all tropics and extratropics (Figures $8 \mathrm{~b}, 8 \mathrm{f}$ and $8 \mathrm{i}$ ). Exception, though, can be found for the EP experiment (Figure 8i), where some low, yet positive, skill is presented on the coastal region of North America and in the Western Pacific. Although the skill values are smaller, those results are similar to that obtained for the unfiltered experiments: while the North Pacific SSTs are a source of predictability for the tropics, the tropics act to decrease the predictability for the North Pacific in seasonal to intraannual time scales. Specifically, the PMM mechanism adds predictability to the tropics in seasonal time scale, and has some contribution for the predictability of the interannual part of the signal; moreover, the atmospheric bridge mechanism does not add predictability for the North Pacific in time scales less than decadal. 
One would think that after the skill is lost it can not be recovered. Curiously, this is not true for those forecasts: at two years, there is a significant increase in the skill for all the experiments, in particular for the experiment including tropics and extratropics. This gain in skill is seen in the Northeastern Pacific along the coast, in the Western Pacific north of the tropics, and in the tropics close to the dateline. The skill decreases for the forecast after three years, but it remains higher than the one at one year. Although LIM is able to identify decaying predictable signals at a certain lead time $\tau$ (represented by $\boldsymbol{B} \boldsymbol{\tau}$ in Equation 3), a cyclic signal can be recovered by the forecast and expressed as an increase in the skill. Particularly, this might be expression of the SSTa "reemergence mechanism" (Alexander and Deser 1995). According to this mechanism, the decorrelation time scale of midlatitude SSTa in successive winters is generally greater than one year. During winter time, temperature anomalies are formed throughout the deep mixed layer. In the spring the mixed layer suddenly shallows, and the winter temperature anomalies can remain below the thin mixed layer during spring and summer. Finally, during the fall the mixed layer deepens again, and the those deeper temperature anomalies are mixed back toward the surface. Although the reemergence is seasonally formed, it can affect the PDO variability on interannual to decadal time scales (Newman et al. 2003; Schneider and Cornuelle 2005). Therefore, the recover in skill after one year of its damping might be an expression of the interannual influence of the reemergence mechanism over the North Pacific.

The interaction between a seasonal process driving an interannual expression can be better explored by analyzing the propagator matrix $\boldsymbol{B}$, as described in Sections 33.2 and 33.3. Figure 10 shows $\boldsymbol{B}$ at different lead times $(\boldsymbol{\tau})$, up to 10 years. The upscale interaction between seasonal and interannual (seasonal modes driving interannual modes) is shown in the submatrix $\boldsymbol{B}_{S I}$. This interaction decreases with lead time, but it persists up to two years, which can represent the reemergence mechanism. On the other hand, the downscale interaction (interannual modes 
driving seasonal modes) do not occur at any lead time (submatrix $\boldsymbol{B}_{I S}$ ).

The forecast for the decadal component of SSTa is presented in Figure 9. There is high predictability of the decadal part of the signal up to one year for the whole North Pacific and tropics, with skill values greater than 0.8 . The exceptions are a circular-shaped region of low skill in the Northwest Pacific, being more clear in the ET experiment (Figure 9i). This circular region correspond to the nodal region of the first decadal EOF, as shown in Figure 7a. When calculating the EOFs excluding the tropics, this border is much more well defined (Figures not shown). Indeed, for the ET experiment the correlations in the circular-shaped region decrease to zero or some negative values in the second year and the skill is almost completely lost in the third year of forecast, with the exception of a coastal region between North Canada and Alaska.

The predictability of the decadal part of SSTa for the Tropical region does not seem to be very sensitive to the inclusion of the North Pacific to build the LIM, differently from the higher frequency variability, which had a significant gain in the predictability when including Extratropical information. There is a loss in skill in the tropics close to the dateline in the first year and beyond, when this low skill is spread eastward. This area with low skill is close to the nodal region of the EOF2 pattern for the decadal component (Figure 7b), which could explain the difficult of a linear model to forecast the SSTa in this region. On the other hand, the skill for the western of the dateline remains high until the fourth year of forecast (Figure 9a to 9h). The decadal variability of SSTa in North Pacific, especially in the Western part, seems to be highly influenced by the Tropical variability. There is a clear loss in the predictability for the extratropics when excluding the Tropical region in the analysis. For the PA experiment, there is predictability up to the fourth year for some regions, while in the ET experiment the predictability is almost completely lost in the third year. Therefore, this shows a one-way interaction between North Pacific and tropics for the decadal part of the signal, where the tropics are a source of predictability for the North Pacific. 
On the other hand, and differently from the higher frequency signals, the North Pacific does not act to increase the predictability for the tropics. This forcing from the tropics to extratropics is consistent with several studies that have identified a communication of the Tropical decadal variability with the North Pacific, via the atmospheric bridges (Alexander et al. 2002, 2010; Zhang et al. 1997). Moreover, this process is identified as one of the contributors to the PDO related variability (Newman et al. 2016).

The propagator matrices (Figure 10) can be used to better explore how this forcing works. The modal interactions between decadal variability with itself (submatrix $\boldsymbol{B}_{D D}$ ) starts to play a role in the third month of lead time, and gets stronger with the increasing of lead time. This modal interaction can be represented by the communication of tropical decadal variability to the extratropics, as stated before (e.g, Newman et al. 2016). Interestingly, though, the interannual variability appears to drive decadal variability at longer lead times. This effect is shown in the submatrices correpondent to the upscale interaction between interannual and decadal modes (submatrices $\boldsymbol{B}_{I D}$, interannual modes driving decadal modes). We observe that this modal interaction starts with about six months and increases up to 10 years. This suggests that not only the decadal tropical variability adds some predictability to the extratropics, but also the interannual variability. Although with the propagator matrix it is not possible to identify the regions where this variability comes from, the leading EOFs allow us to identify the patterns with that dominate the variability at each time scale (Figure 7). We showed that a PDO-like patterns dominates the decadal variability, while an ENSO-like patterns dominates the interannual variability. Therefore, when excluding the tropics from the model, the predictable signals from the tropics, either the decadal and the interannual ENSO, are lost and the predictability for the PDO region is damped. 


\section{Summary and concluding remarks}

The forecast skill of Pacific sea surface temperature anomalies (SSTa) on seasonal, interanual, and decadal time scales has been tested using a suite of linear inverse models (LIM). The forecast skill was first evaluated to the North Pacific plus the Tropical Pacific $\left(15^{\circ} \mathrm{S}\right.$ to $\left.60^{\circ} \mathrm{N}\right)$ and then separately for each of those regions. By separating the variability into these time scales and regions, we aimed to identify how interactions between time scales affect predictability and how the two regions affect each other in driving predictable components linked to ENSO or intrinsic mid-latitude interactions.

For the seasonal time scale, our results revealed that LIM has a good forecast skill $(\rho>0.6)$ in some areas up to 9 months. However, this predictability varied for each region included in the model. Specifically, we showed that the inclusion of data from the extratropics enhanced the forecast skill of the tropics, suggesting that there is a communication between those two regions on seasonal time scales. Moreover, since LIM assumes that the evolution of a system is approximated by linear dynamics, the mechanism associated with this interaction might be essentially linear. Therefore, we suggested that this enhanced predictability seen in the Tropical regions for LIM-PA can be due to the Pacific Meridional Mode (PMM) propagating the mid-latitude SST anomalies associated with the North Pacific Oscillation (NPO).

Those results were also contrasted to the GCMs of the North-American Multi Model Ensemble (NMME) for two regions in the Pacific: Niño 3.4 and the California Current System (CCS). Although both LIM and NMME have comparable forecast skill for some initialization months in Niño 3.4 region, the expression of the Spring Predictability Barrier (SPB) is much more evident in the LIM forecasts. Specifically, the Spring SSTa forecast with LIM presents a decrease in the skill which is more evident than the NMME forecast, while for the other months both models have 
similar skill. LIM assumes that the nonlinear part of the signal is unpredictable, so this skill comes exclusively from the linear part. Since the skill of an empirical linear model (LIM) is comparable to the skill of a high dimensional nonlinear coupled GCM (NMME) for certain months, we suggested that the nonlinear SSTa variability for this period is either essentially stochastic or not well represented in current GCMs.

In the CCS, LIM overall perform better than NMME models, although both models have good skill across nearly all the initialization months up to six months of forecast. By comparing LIM experiments (including or excluding the tropics), tropical and local variability seems to play a role in the CCS variability, depending on the period that is being considered. In a period with high (weak) ENSO variability, the Tropical signal increases (decreases) the skill for the CCS forecast. The forecast skill for a LIM formulated by using modes of variability from a filtered time series was performed to evaluate the long term predictability. For the interannual part of the signal, the extratropics act as a source of predictability to the tropics. Additionally, the regions with the highest skill in the interannual forecasts are very similar to the ones in the seasonal forecasts. We suggested that the PMM mechanism adds predictability to the tropics in seasonal to interannual time scales when forecasting up to one year. The LIM configured only with the decadal component has good forecast $(\rho>0.8)$ up to three years for most part of the Pacific, especially for the extratropics and for the experiment including the tropics. Therefore, the interaction between tropics and extratropics for the decadal components acts the other way around when compared to the higher frequency variability: there is a significant increase in the forecast skill in the extratropics when including the tropics, although the Extratropical region does not act to improve the forecast skill for the tropics. We suggested that this forcing occurs due to the atmospheric bridge mechanism, that is one of the contributors to the PDO-related variability.

Finally, we explore the coupling among time scales using the propagator matrices (Eq. 3), that 
show the modal interaction between the leading modes of each filtered time scale, as presented in Eq. 9. We show that the upscale interaction between interannual and decadal modes persists up to 10 years, which is an indication that the predictability that is added from the tropics corresponds not only to tropical decadal variability, but also the interannual. These results indicate the importance of temporal scale interactions in improving predictability on decadal timescales.

Acknowledgments. We are grateful for the National Science Foundation (OCE1419306) and the National Oceanic and Atmospheric Administration (NOAA-MAPP; NA17OAR4310106) for funding that supported this research. Daniela F. Dias was partially supported by the Brazilian National Council for Scientific and Technological Development $(\mathrm{CNPq})$ under the grant 221222/2014-6.

\section{References}

Alexander, M. A., I. Bladé, M. Newman, J. R. Lanzante, N. C. Lau, and J. D. Scott, 2002: The atmospheric bridge: The influence of ENSO teleconnections on air-sea interaction over the global oceans. Journal of Climate, 15 (16), 2205-2231, doi:10.1175/1520-0442.

Alexander, M. a., and C. Deser, 1995: A Mechanism for the Recurrence of Wintertime Midlatitude SST Anomalies. Journal of Physical Oceanography, 25, 122-137, doi:10.1175/1520-0485.

Alexander, M. A., L. Mastrova, C. Penland, J. D. Scott, and P. Chang, 2008: Forecasting Pacific SSTs: Linear Inverse Model Predictions of the PDO. Journal of Climate, 21 (2), 385-402, doi:10.1175/2007JCLI1849.1

Alexander, M. A., D. J. Vimont, P. Chang, and J. D. Scott, 2010: The Impact of Extratropical Atmospheric Variability on ENSO : Testing the Seasonal Footprinting Mechanism Using Coupled Model Experiments. Journal of Climate, 23 (11), 2885-2901, doi:10.1175/2010JCLI3205.1. 
Allen, J. T., M. K. Tippett, and A. H. Sobel, 2015: Influence of the El Niño/Southern Oscillation on tornado and hail frequency in the United States. Nature Geoscience, 8 (4), 278-283, doi: 10.1038/ngeo2385.

Barnston, A. G., and C. F. Ropelewski, 1992: Prediction of ENSO episodes using canonical correlation analysis. 1316-1345 pp., doi:10.1175/1520-0442.

Barnston, A. G., M. K. Tippett, M. Ranganathan, and M. L. L 'heureux, 2017: Deterministic skill of ENSO predictions from the North American Multimodel Ensemble. Climate Dynamics, 1-20, doi:10.1007/s00382-017-3603-3.

Battisti, D. S., and A. C. Hirst, 1989: Interannual Variability in a Tropical AtmosphereOcean Model: Influence of the Basic State, Ocean Geometry and Nonlinearity. 1687-1712 pp., doi: $10.1175 / 1520-0469$.

Becker, E., H. Van den Dool, and Q. Zhang, 2014: Predictability and forecast skill in NMME. Journal of Climate, 27 (15), 5891-5906, doi:10.1175/JCLI-D-13-00597.1.

Becker, E., H. Van den Dool, and Q. Zhang, 2016: Probabilistic seasonal forecasts in the North American Multimodel Ensemble: A baseline skill assessment. Journal of Climate, 29 (8), 30153026, doi:10.1175/JCLI-D-14-00862.1.

Bjerknes, J., 1966: A possible response of the atmospheric Hadley circulation to equatorial anomalies of ocean temperature. Tellus, 18 (4), 820-829, doi:10.1111/j.2153-3490.1966.tb00303.x.

Capotondi, A., and P. D. Sardeshmukh, 2015: Optimal precursors of different types of ENSO events. Geophysical Research Letters, 42 (22), 9952-9960, doi:10.1002/2015GL066171. 
Cavanaugh, N. R., T. Allen, A. Subramanian, B. Mapes, H. Seo, and A. J. Miller, 2014: The skill of atmospheric linear inverse models in hindcasting the Madden-Julian Oscillation. Climate Dynamics, 44 (3-4), 897-906, doi:10.1007/s00382-014-2181-x.

Ceballos, L. I., E. Di Lorenzo, C. D. Hoyos, N. Schneider, and B. Taguchi, 2009: North Pacific gyre oscillation synchronizes climate fluctuations in the eastern and western boundary systems. Journal of Climate, 22 (19), 5163-5174, doi:10.1175/2009JCLI2848.1.

Chang, P., L. Zhang, R. Saravanan, D. J. Vimont, J. C. H. Chiang, L. Ji, H. Seidel, and M. K. Tippett, 2007: Pacific meridional mode and El Niño - Southern oscillation. Geophysical Research Letters, 34 (16), doi:10.1029/2007GL030302.

Chen, C., M. A. Cane, N. Henderson, D. E. Lee, D. Chapman, D. Kondrashov, and M. D. Chekroun, 2016: Diversity, nonlinearity, seasonality, and memory effect in ENSO simulation and prediction using empirical model reduction. Journal of Climate, 29 (5), 1809-1830, doi: 10.1175/JCLI-D-15-0372.1.

Chiang, J. C. H., and D. J. Vimont, 2004: Analogous Pacific and Atlantic Meridional Modes of Tropical Atmosphere-Ocean Variability *. Journal of Climate, 17 (21), 4143-4158.

Clayson, C. A., and D. Weitlich, 2007: Variability of tropical diurnal sea surface temperature. Journal of Climate, 20 (2), 334-352, doi:10.1175/JCLI3999.1.

Di Lorenzo, E., G. Liguori, N. Schneider, J. C. Furtado, B. T. Anderson, and M. A. Alexander, 2015: ENSO and meridional modes: A null hypothesis for Pacific climate variability. Geophysical Research Letters, 42 (21), 9440-9448, doi:10.1002/2015GL066281.

Di Lorenzo, E., and Coauthors, 2008: North Pacific Gyre Oscillation links ocean climate and ecosystem change. Geophysical Research Letters, 35 (8), doi:10.1029/2007GL032838. 
Duan, W., and C. Wei, 2013: The 'spring predictability barrier' for ENSO predictions and its possible mechanism: Results from a fully coupled model. International Journal of Climatology, 33 (5), 1280-1292, doi:10.1002/joc.3513.

Eccles, F., and E. Tziperman, 2004: Nonlinear effects on ENSO's period. Journal of the Atmospheric Sciences, 61 (4), 474-482, doi:10.1175/1520-0469.

Frankignoul, C., and K. Hasselmann, 1977: Stochastic climate models, Part II Application to sea-surface temperature anomalies and thermocline variability. Tellus, 29 (4), 289-305, doi: 10.3402/tellusa.v29i4.11362.

Grimm, A. M., and R. G. Tedeschi, 2009: ENSO and extreme rainfall events in South America. Journal of Climate, 22 (7), 1589-1609, doi:10.1175/2008JCLI2429.1.

Henley, B. J., J. Gergis, D. J. Karoly, S. Power, J. Kennedy, and C. K. Folland, 2015: A Tripole Index for the Interdecadal Pacific Oscillation. Climate Dynamics, 45 (11-12), 3077-3090, doi: $10.1007 / \mathrm{s} 00382-015-2525-1$.

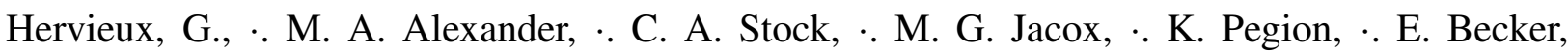
$\therefore$ F. Castruccio, and $\cdot$ D. Tommasi, 2017: More reliable coastal SST forecasts from the North American multimodel ensemble. Climate Dynamics, 1-16, doi:10.1007/s00382-017-3652-7.

Huddart, B., A. Subramanian, L. Zanna, and T. Palmer, 2016: Seasonal and decadal forecasts of Atlantic Sea surface temperatures using a linear inverse model. Climate Dynamics, 1-13, doi:10.1007/s00382-016-3375-1.

Jacox, M. G., M. A. Alexander, C. A. Stock, and G. Hervieux, 2015: On the skill of seasonal sea surface temperature forecasts in the California Current System and its connection to ENSO variability. Climate Dynamics, 1-15, doi:10.1007/s00382-017-3608. 
Jin, E. K., and Coauthors, 2008: Current status of ENSO prediction skill in coupled ocean- atmosphere models. Climate Dynamics, 31, 647-664, doi:10.1007/s00382-008-0397-3.

Kim, S. T., and J. Y. Yu, 2012: The two types of ENSO in CMIP5 models. Geophysical Research Letters, 39 (11), 1-6, doi:10.1029/2012GL052006.

Kirtman, B. P., and Coauthors, 2014: The North American multimodel ensemble: Phase-1 seasonal-to-interannual prediction; phase-2 toward developing intraseasonal prediction. Bulletin of the American Meteorological Society, 95 (4), 585-601, doi:10.1175/BAMS-D-12-00050.1.

L'Heureux, M. L., M. K. Tippett, and A. G. Barnston, 2015: Characterizing ENSO Coupled Variability and Its Impact on North American Seasonal Precipitation and Temperature. Journal of Climate, 28 (10), 4231-4245, doi:10.1175/JCLI-D-14-00508.1.

Linkin, M. E., and S. Nigam, 2008: The North Pacific Oscillation-West Pacific teleconnection pattern: Mature-phase structure and winter impacts. Journal of Climate, 21 (9), 1979-1997, doi:10.1175/2007JCLI2048.1.

Lopez, H., and B. P. Kirtman, 2014: WWBs, ENSO predictability, the spring barrier and extreme events. Journal of Geophysical Research, 119 (17), doi:10.1002/2014JD021908.

MacMynowski, D. G., and E. Tziperman, 2008: Factors Affecting ENSO’s Period. Journal of the Atmospheric Sciences, 65 (5), 1570-1586, doi:10.1175/2007JAS2520.1.

Majda, A. J., C. Franzke, and D. Crommelin, 2009: Normal forms for reduced stochastic climate models. Proceedings of the National Academy of Sciences, 106 (10), 3649--3653.

Majda, a. J., I. Timofeyev, and Vanden Eijnden E, 1999: Models for stochastic climate prediction. Proceedings of the National Academy of Sciences of the United States of America, 96 (26), 14 687-91, doi:10.1073/pnas.96.26.14687. 
Mantua, N. J., S. R. Hare, Y. Zhang, J. M. Wallace, and R. Francis, 1997: A Pacific interdecadal climate oscillation with impacts on salmon production. Bull. Am. Meteorol., (January), 10691079, doi:10.1175/1520-0477.

McEwen, G. F., 1914: Peculiarities of the California Climate. Monthly Weather Review, 42, 14-25, doi:https://doi.org/10.1175/1520-0493.

McPhaden, M. J., 2003: Tropical Pacific Ocean heat content variations and ENSO persistence barriers. Geophysical Research Letters, 30 (9), 1480, doi:10.1029/2003GL016872.

Meehl, G. A., and Coauthors, 2014: Decadal climate prediction an update from the trenches. Bulletin of the American Meteorological Society, 95 (2), 243-267, doi:10.1175/ BAMS-D-12-00241.1.

Miller, A. J., and N. Schneider, 2000: Interdecadal climate regime dynamics in the North Pacific Ocean: Theories, observations and ecosystem impacts. Progress in Oceanography, 47 (2-4), 355-379, doi:10.1016/S0079-6611(00)00044-6.

Newman, M., 2007: Interannual to decadal predictability of tropical and North Pacific sea surface temperatures. Journal of Climate, 20 (11), 2333-2356, doi:10.1175/JCLI4165.1.

Newman, M., 2013: An empirical benchmark for decadal forecasts of global surface temperature anomalies. Journal of Climate, 26 (14), 5260-5269, doi:10.1175/JCLI-D-12-00590.1.

Newman, M., G. P. Compo, and M. A. Alexander, 2003: ENSO-forced variability of the Pacific decadal oscillation. Journal of Climate, 16 (23), 3853-3857, doi:10.1175/1520-0442.

Newman, M., and P. D. Sardeshmukh, 2017: Are we near the predictability limit of tropical Indo-Pacific sea surface temperatures? Geophysical Research Letters, 1-10, doi:10.1002/ 2017GL074088. 
Newman, M., P. D. Sardeshmukh, and C. Penland, 2009: How important is air-sea coupling in ENSO and MJO evolution? Journal of Climate, 22 (11), 2958-2977, doi:10.1175/ 2008JCLI2659.1.

Newman, M., and Coauthors, 2016: The Pacific decadal oscillation, revisited. Journal of Climate, 29 (12), 4399-4427, doi:10.1175/JCLI-D-15-0508.1.

Penland, C., 1989: Random Forcing and Forecasting Using Principal Oscillation Pattern Analysis. 2165-2185 pp., doi:10.1175/1520-0493.

Penland, C., and T. Magorian, 1993: Prediction of Niño 3 sea surface temperatures using linear inverse modeling. 1067-1076 pp., doi:10.1175/1520-0442.

Penland, C., and L. Matrosova, 1994: A Balance Condition for Stochastic Numerical Models with Application to the El Niño-Southern Oscillation. 1352-1372 pp., doi:10.1175/1520-0442.

Penland, C., and P. D. Sardeshmukh, 1995: The Optimal Growth of Tropical Sea Surface Temperature Anomalies. 1999-2024 pp., doi:10.1175/1520-0442.

Power, S., T. Casey, C. Folland, A. Colman, and V. Mehta, 1999: Inter-decadal modulation of the impact of ENSO on Australia. Climate Dynamics, 15 (5), 319-324, doi:10.1007/ s003820050284.

Qiu, B., 2003: Kuroshio Extension Variability and Forcing of the Pacific Decadal Oscillations: Responses and Potential Feedback. Journal of Physical Oceanography, 33 (12), 2465-2482, doi:10.1175/2459.1.

Rayner, N. A., D. Parker, E. Horton, C. Folland, L. Alexander, D. Rowell, E. Kent, and A. Kaplan, 2003: Global analyses of sea surface temperature, sea ice, and night marine air temperature 
since the late nineteenth century. Journal of Geophysical Research, 108 (D14), 4407, doi:10. 1029/2002JD002670.

Schneider, N., and B. D. Cornuelle, 2005: The forcing of the Pacific Decadal Oscillation. Journal of Climate, 18 (21), 4355-4373, doi:10.1175/JCLI3527.1.

Taguchi, B., S. P. Xie, N. Schneider, M. Nonaka, H. Sasaki, and Y. Sasai, 2007: Decadal variability of the Kuroshio Extension: Observations and an eddy-resolving model hindcast. Journal of Climate, 20 (11), 2357-2377, doi:10.1175/JCLI4142.1.

Tanahashi, S., H. Kawamura, T. Takahashi, and H. Yusa, 2003: Diurnal variations of sea surface temperature over the wide-ranging ocean using VISSR on board GMS. Journal of Geophysical Research, 108 (C7), 1-15, doi:10.1029/2002JC001313.

Thomas, E. E., and D. J. Vimont, 2016: Modeling the mechanisms of linear and nonlinear ENSO responses to the pacific meridional mode. Journal of Climate, $\mathbf{2 9}$ (24), 8745-8761, doi:10.1175/ JCLI-D-16-0090.1.

Vimont, D. J., M. Alexander, and A. Fontaine, 2009: Midlatitude excitation of tropical variability in the pacific: The role of thermodynamic coupling and seasonality. Journal of Climate, 22 (3), 518-534, doi:10.1175/2008JCLI2220.1.

Vimont, D. J., M. A. Alexander, and M. Newman, 2014: Optimal growth of Central and East Pacific ENSO events. Geophysical Research Letters, 41, 4027-4034, doi:10.1002/2014GL059997.

Vimont, D. J., D. S. Battisti, and A. C. Hirst, 2001: Footprinting: A seasonal connection between the tropics and mid-latitudes. Geophysical Research Letters, 28 (20), 3923-3926, doi:10.1029/ $2001 \mathrm{GL} 013435$. 
Vimont, D. J., J. M. Wallace, and D. S. Battisti, 2003: The seasonal footprinting mechanism in the Pacific: Implications for ENSO. Journal of Climate, 16 (16), 2668-2675, doi:10.1175/ 1520-0442.

Webster, P. J., and S. Yang, 1992: Monsoon and ENSO: Selectively interactive systems. Quart. J. Roy. Meteorol. Soc., 118 (507), 877-926.

Xue, Y., M. Chen, A. Kumar, Z. Z. Hu, and W. Wang, 2013: Prediction skill and bias of tropical pacific sea surface temperatures in the NCEP climate forecast system version 2. Journal of Climate, 26 (15), 5358-5378, doi:10.1175/JCLI-D-12-00600.1.

Yeh, S. W., B. P. Kirtman, J. S. Kug, W. Park, and M. Latif, 2011: Natural variability of the central Pacific El Niño event on multi-centennial timescales. Geophysical Research Letters, 38 (2), 2-6, doi:10.1029/2010GL045886.

Yu, J. Y., and S. T. Kim, 2011: Relationships between extratropical sea level pressure variations and the central Pacific and eastern Pacific types of ENSO. Journal of Climate, 24 (3), 708-720, doi:10.1175/2010JCLI3688.1.

Zanna, L., 2012: Forecast skill and predictability of observed atlantic sea surface temperatures. Journal of Climate, 25 (14), 5047-5056, doi:10.1175/JCLI-D-11-00539.1.

Zhang, Y. J., J. M. Wallace, and D. S. Battisti, 1997: ENSO-like interdecadal variability: 1900-93. Journal of Climate, 10 (5), 1004-1020, doi:10.1175/1520-0442.

Zhao, M., H. H. Hendon, O. Alves, G. Liu, and G. Wang, 2016: Weakened Eastern Pacific El Niño predictability in the early Twenty-First Century. Journal of Climate, 29 (18), 6805-6822, doi:10.1175/JCLI-D-15-0876.1. 


\section{LIST OF FIGURES}

Fig. 1. Maps of temporal correlation for the SST anomalies between the LIM seasonal forecast and observations, for different lead times. The verification period used was 1950 - 1965. a - d: LIM trained using data for the whole domain (experiment PA50); e - h: LIM trained only with data from the tropical region (experiment TP50); i - l: LIM trained with data only from the extratropics (experiment ET50).

Fig. 2. Same as Figure 1, but using data from 1995 to 2010 as the verification period (a - d: experiment PA95; e - h: experiment TP95; and $\mathbf{i}$ - l: experiment ET95).

Fig. 3. Correlations for each start month and lead time between LIMs forecasts and observations (upper panels) and between NMME models and observations (lower panels) for the Niño 3.4 region

Fig. 4. Seasonally averaged root mean square error of the SSTa forecast for Niño 3.4 made using four different LIM experiments (LIM-PA50, LIM-TP50, LIM-PA95 and LIM-TP95) and three NMME models (CESM1, CanCM3 and CanCM4). The vertical bars represent the 95\% confidence interval standard errors.

Fig. 5. Same as Figure 3, but for the CCS

Fig. 6. Same as Figure 4, but for the CCS region

Fig. 7. The three leading EOFs for the North Pacific and tropics for each time scale (decadal (D), interannual (I) and seasonal(S)), with the variance explained given in parenthesis.

Fig. 8. Maps of temporal correlation for the interannual component of the SST anomalies, for different lead times. LIM was constructed using both the decadal and the higher frequency components. a - d: LIM trained using data for the whole domain (experiment PA); $\mathbf{e}-\mathbf{h}$ : LIM trained only with data from the tropical region (experiment TP); $\mathbf{i}-\mathbf{l}$ : LIM trained with data only from the extratropics (experiment ET).

Fig. 9. Same as Figure 8, but for the decadal component of SST anomalies.

Fig. 10. Propagator matrices constructed from the 20 lead EOFs of each time scale using data from the whole domain (PA), at various lead times. The dotted lines indicated are the boundaries for the submatrices of the interactions between each time scale. $\boldsymbol{B}_{D D}, \boldsymbol{B}_{I I}$ and $\boldsymbol{B}_{I I}$ represent the interaction between each time scale with itself; $\boldsymbol{B}_{D I}$ and $\boldsymbol{B}_{D S}$ represent the decadal downscale interactions (decadal modes driving interannual and seasonal modes); $\boldsymbol{B}_{I S}$ represents the interannual downscale interaction (interannual modes driving seasonal modes); $\boldsymbol{B}_{I D}$ represents the interannual upscale interactions (interannual modes driving decadal modes); and $\boldsymbol{B}_{S D}$ and $\boldsymbol{B}_{S I}$ represent the seasonal upscale interactions (seasonal modes driving interannual and decadal modes). 

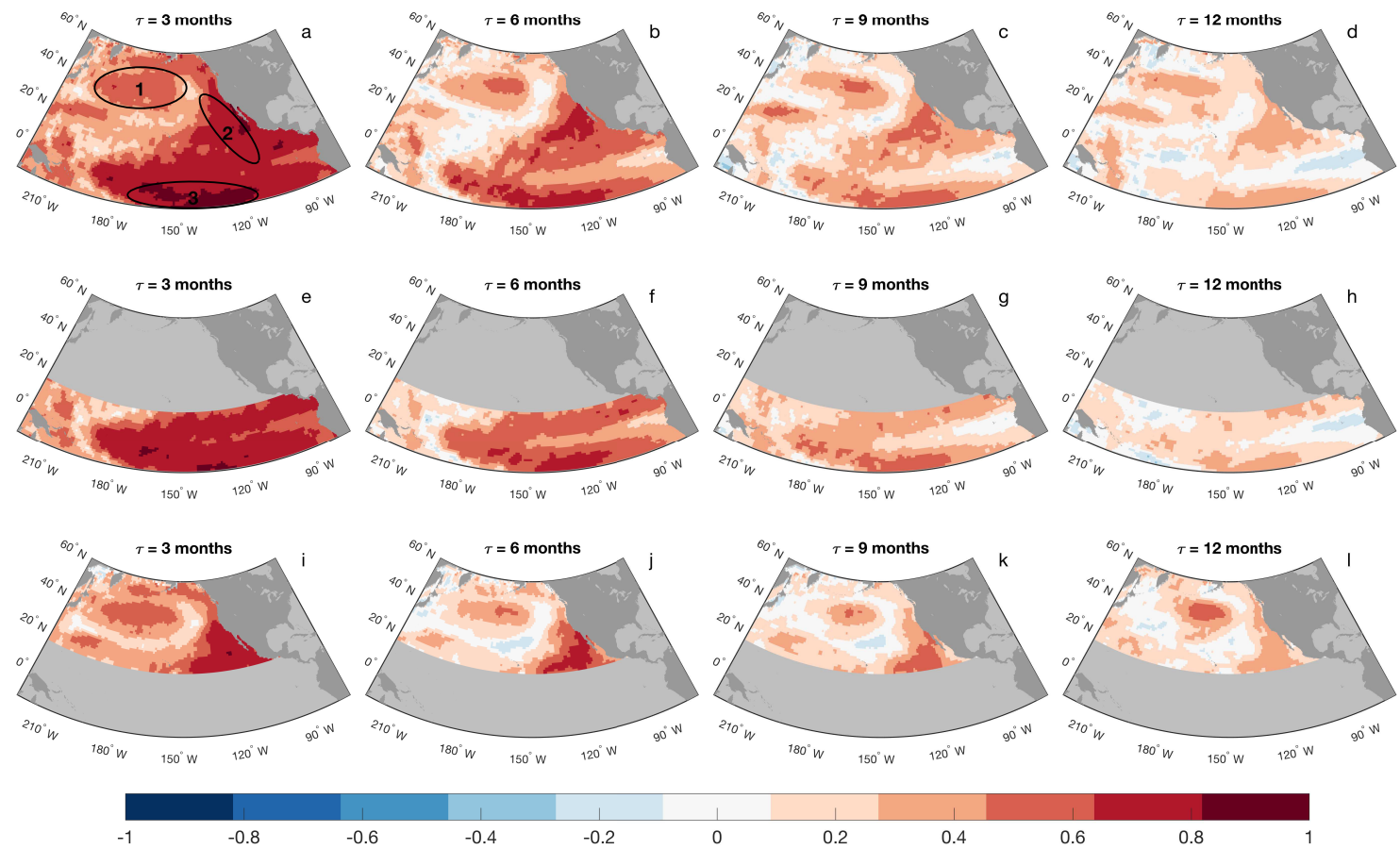

FIG. 1. Maps of temporal correlation for the SST anomalies between the LIM seasonal forecast and observations, for different lead times. The verification period used was 1950 - 1965. a - d: LIM trained using data for the whole domain (experiment PA50); e - h: LIM trained only with data from the tropical region (experiment TP50); i - I: LIM trained with data only from the extratropics (experiment ET50). 

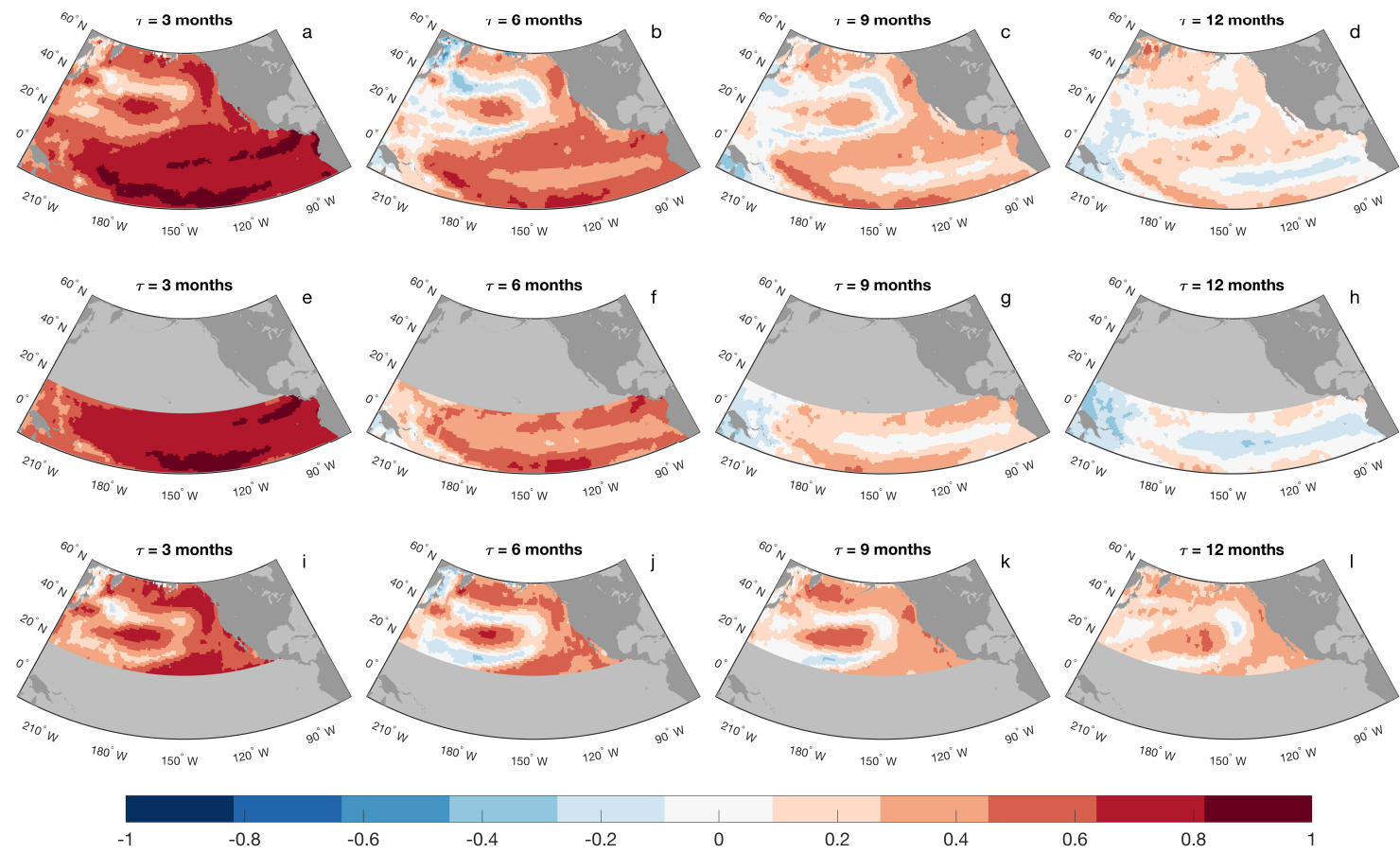

$-0.6$
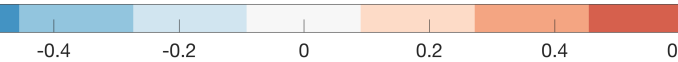

0.6

0.8

FIG. 2. Same as Figure 1, but using data from 1995 to 2010 as the verification period (a - d: experiment PA95; e - h: experiment TP95; and i - l: experiment ET95). 
Nino 3.4
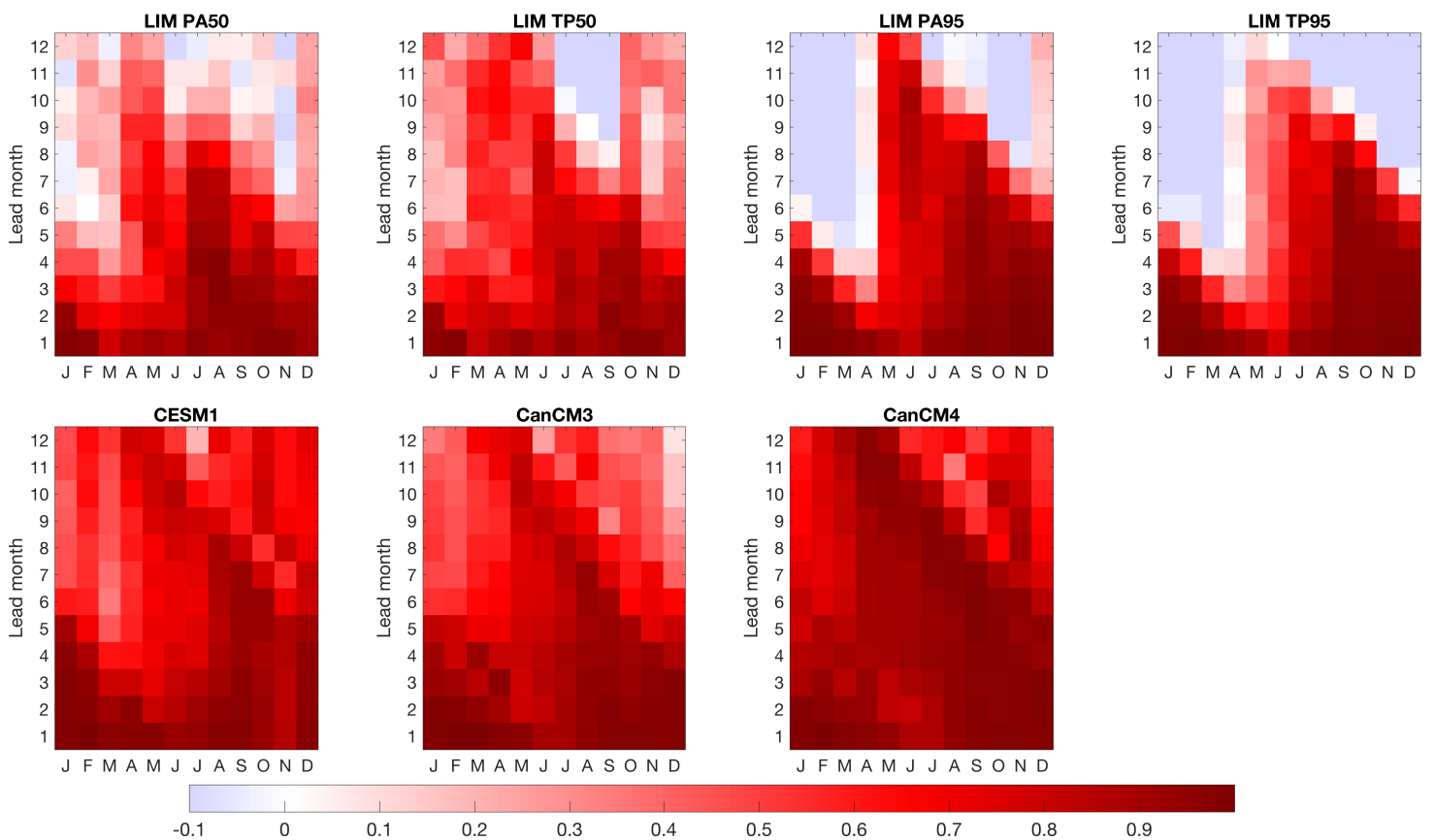

FIG. 3. Correlations for each start month and lead time between LIMs forecasts and observations (upper panels) and between NMME models and observations (lower panels) for the Niño 3.4 region 
Nino 3.4
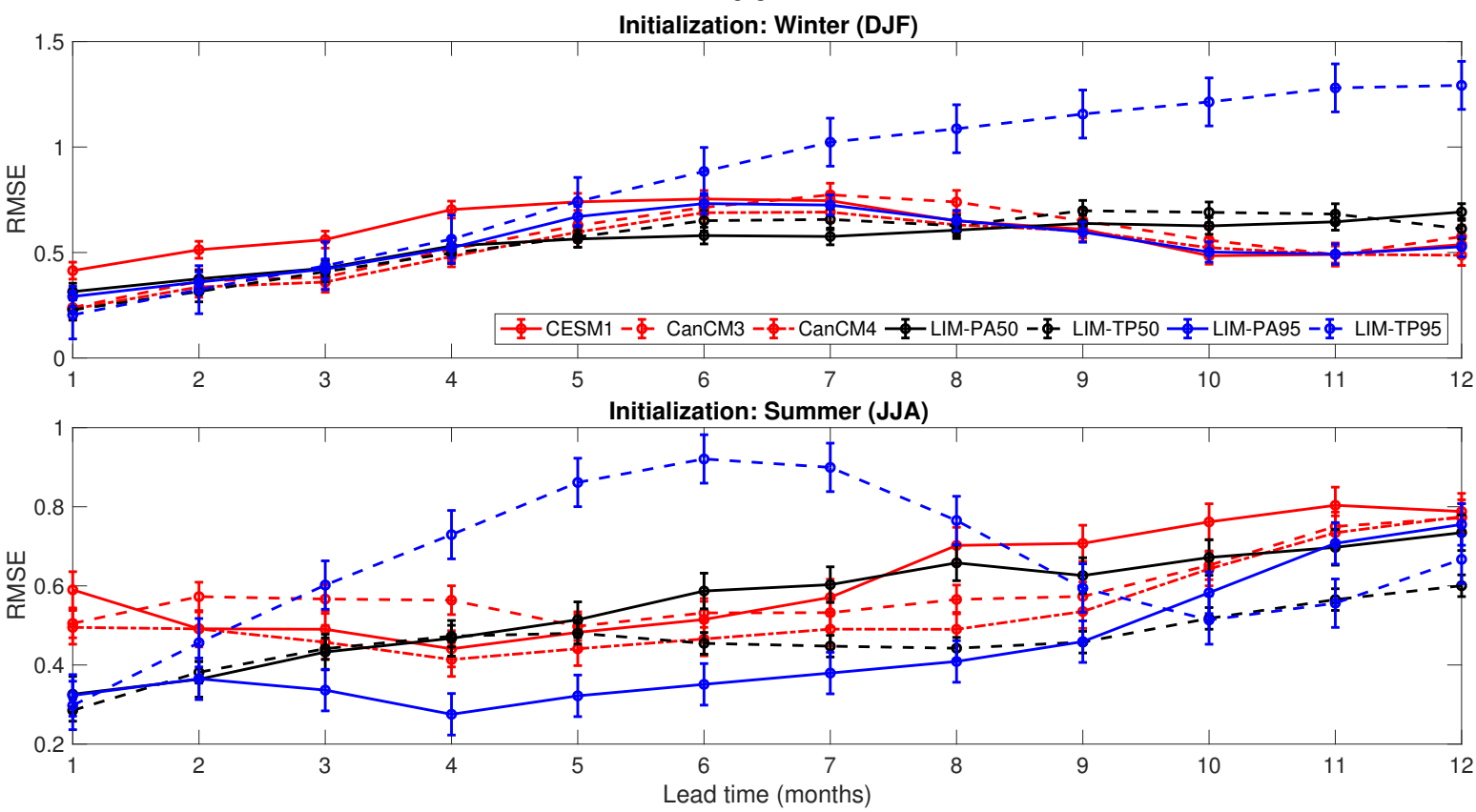

FIG. 4. Seasonally averaged root mean square error of the SSTa forecast for Niño 3.4 made using four different LIM experiments (LIM-PA50, LIM-TP50, LIM-PA95 and LIM-TP95) and three NMME models (CESM1,

CanCM3 and CanCM4). The vertical bars represent the 95\% confidence interval standard errors. 
California Current System
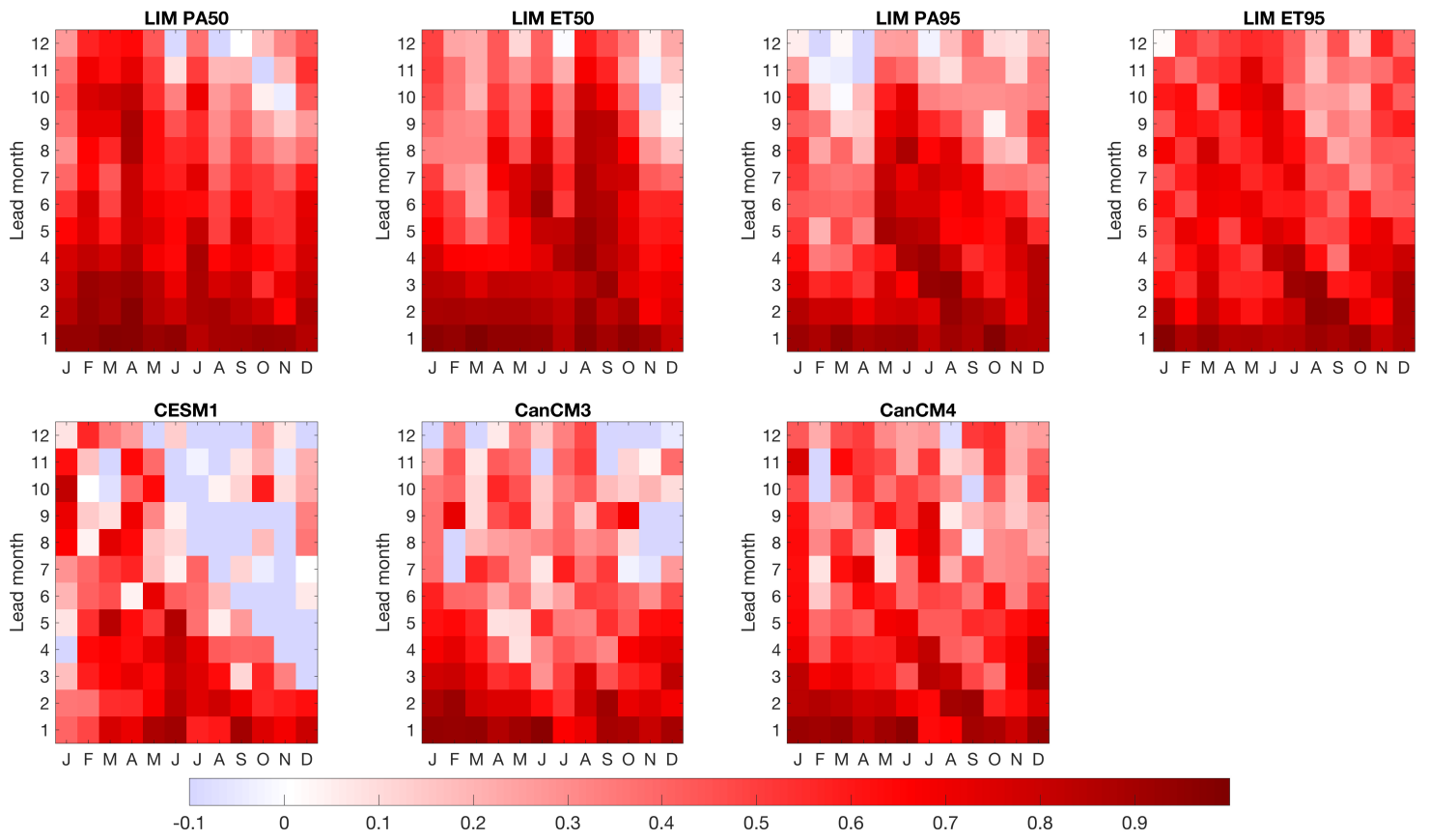

FIG. 5. Same as Figure 3, but for the CCS 

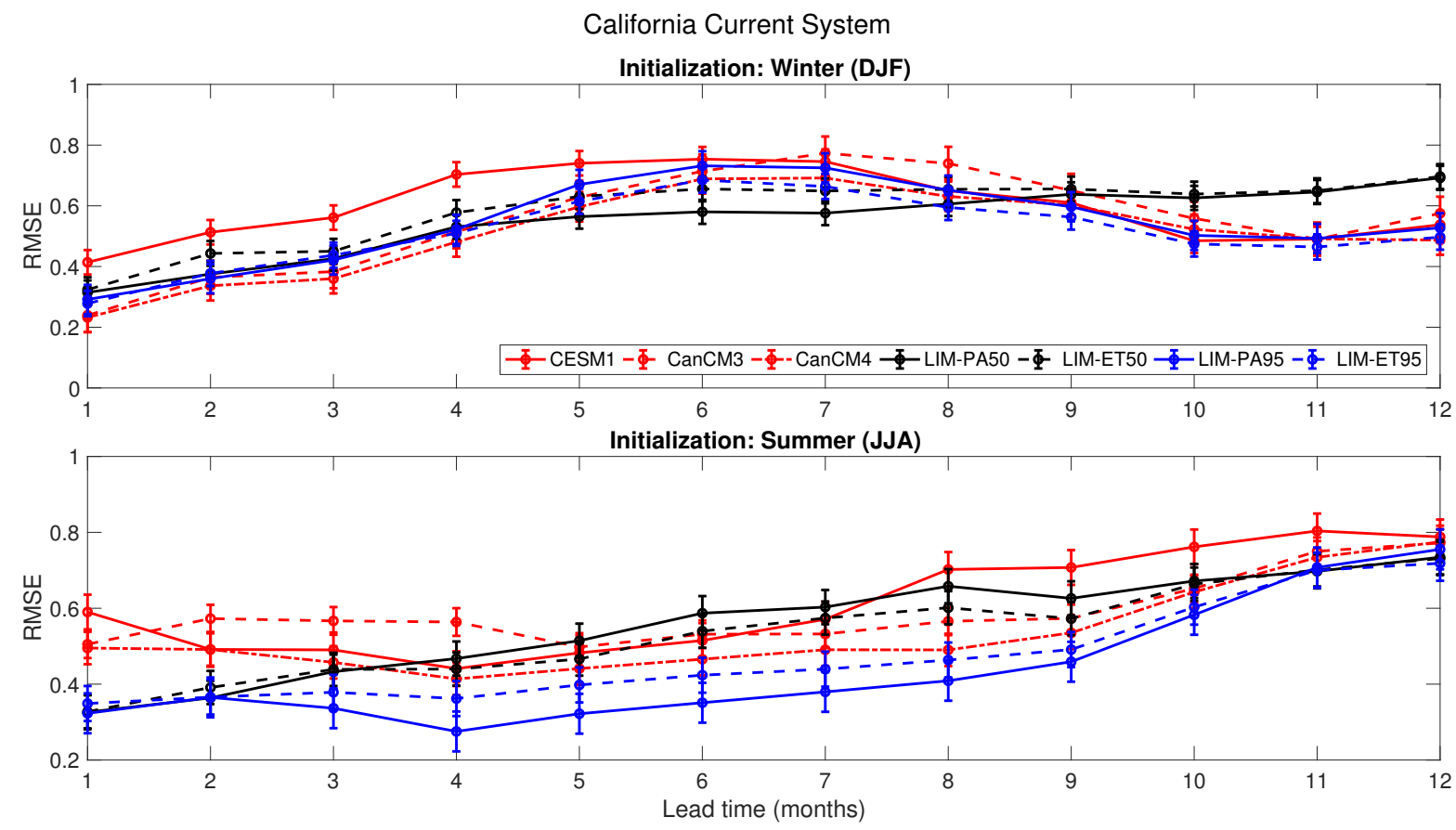

FIG. 6. Same as Figure 4, but for the CCS region 

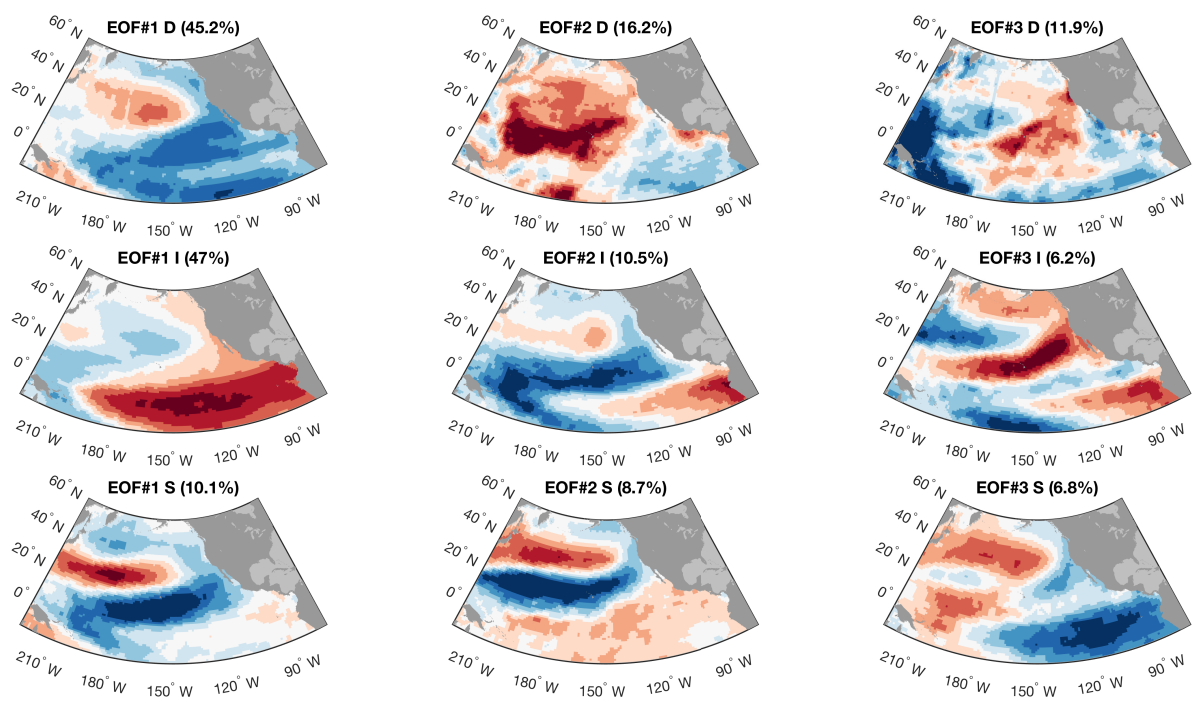

${ }^{6} 0^{\circ} \mathrm{N} \quad \mathrm{EOF} \# 3 \mathrm{~S}(6.8 \%)$

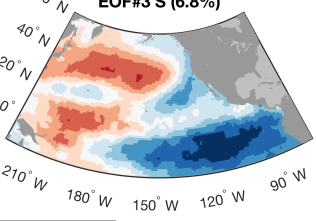

0

FIG. 7. The three leading EOFs for the North Pacific and tropics for each time scale (decadal (D), interannual

(I) and seasonal(S)), with the variance explained given in parenthesis. 

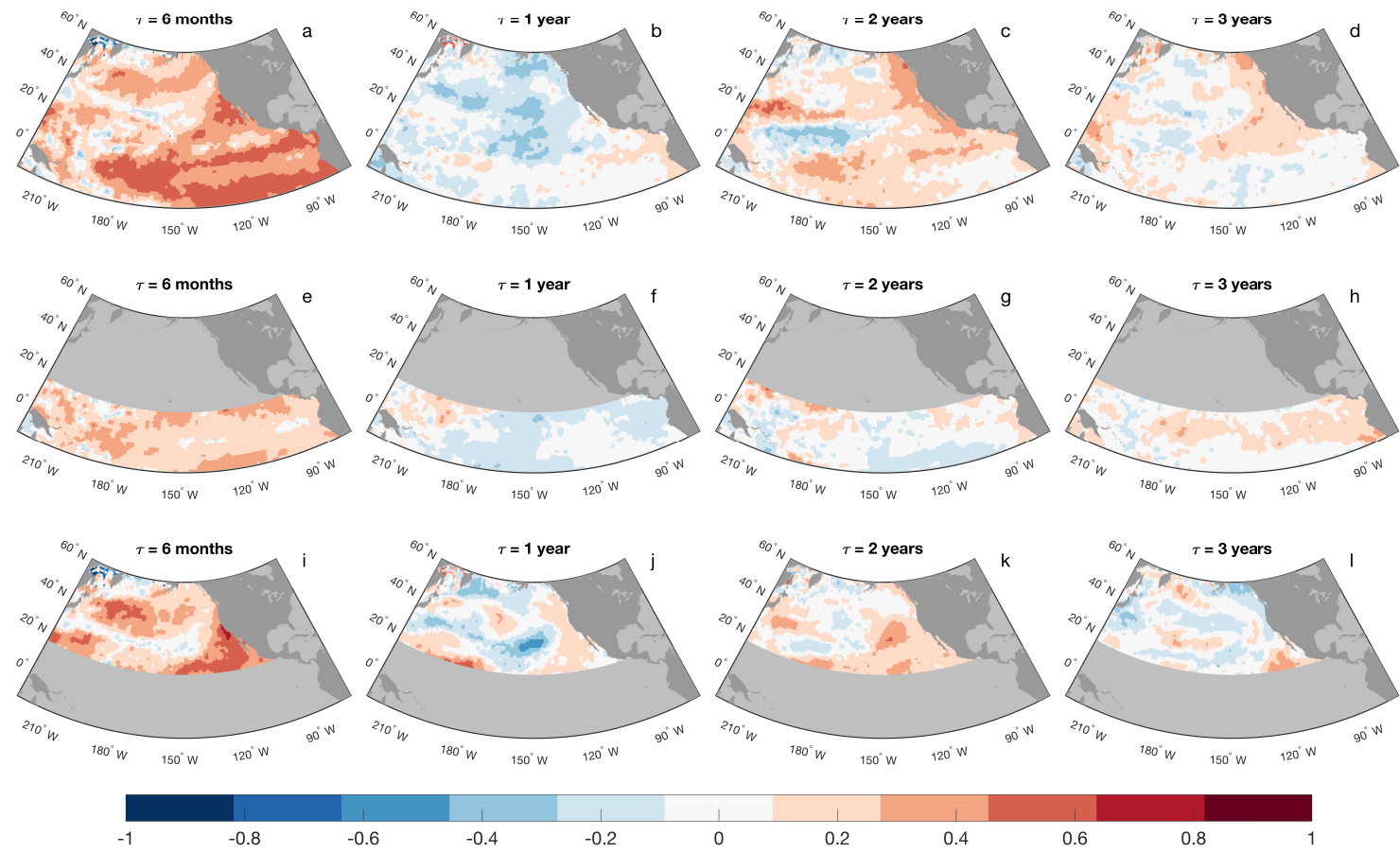

0.8

FIG. 8. Maps of temporal correlation for the interannual component of the SST anomalies, for different lead times. LIM was constructed using both the decadal and the higher frequency components. a - d: LIM trained using data for the whole domain (experiment PA); $\mathbf{e}-\mathbf{h}$ : LIM trained only with data from the tropical region (experiment TP); i - l: LIM trained with data only from the extratropics (experiment ET). 

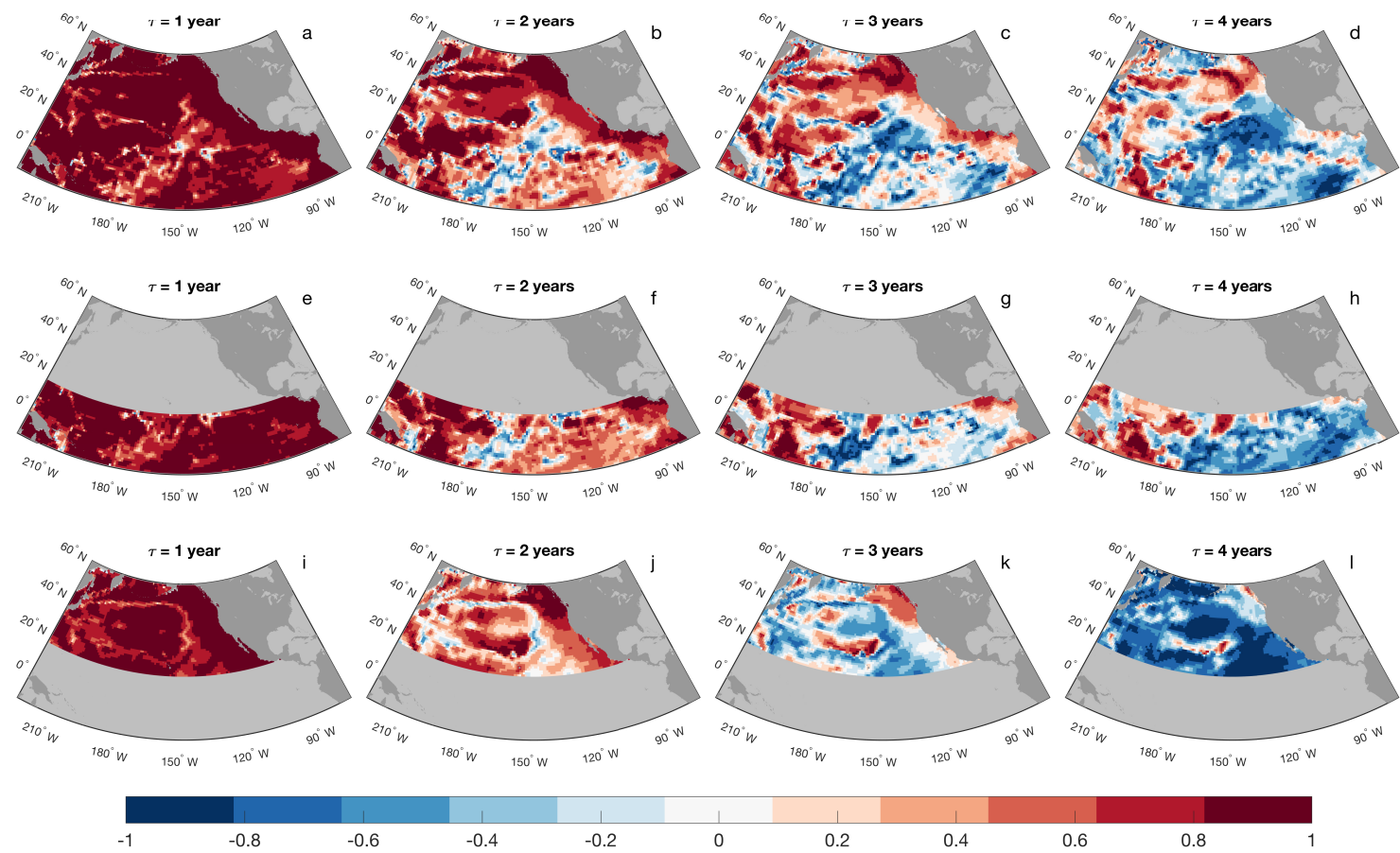

FIG. 9. Same as Figure 8, but for the decadal component of SST anomalies. 

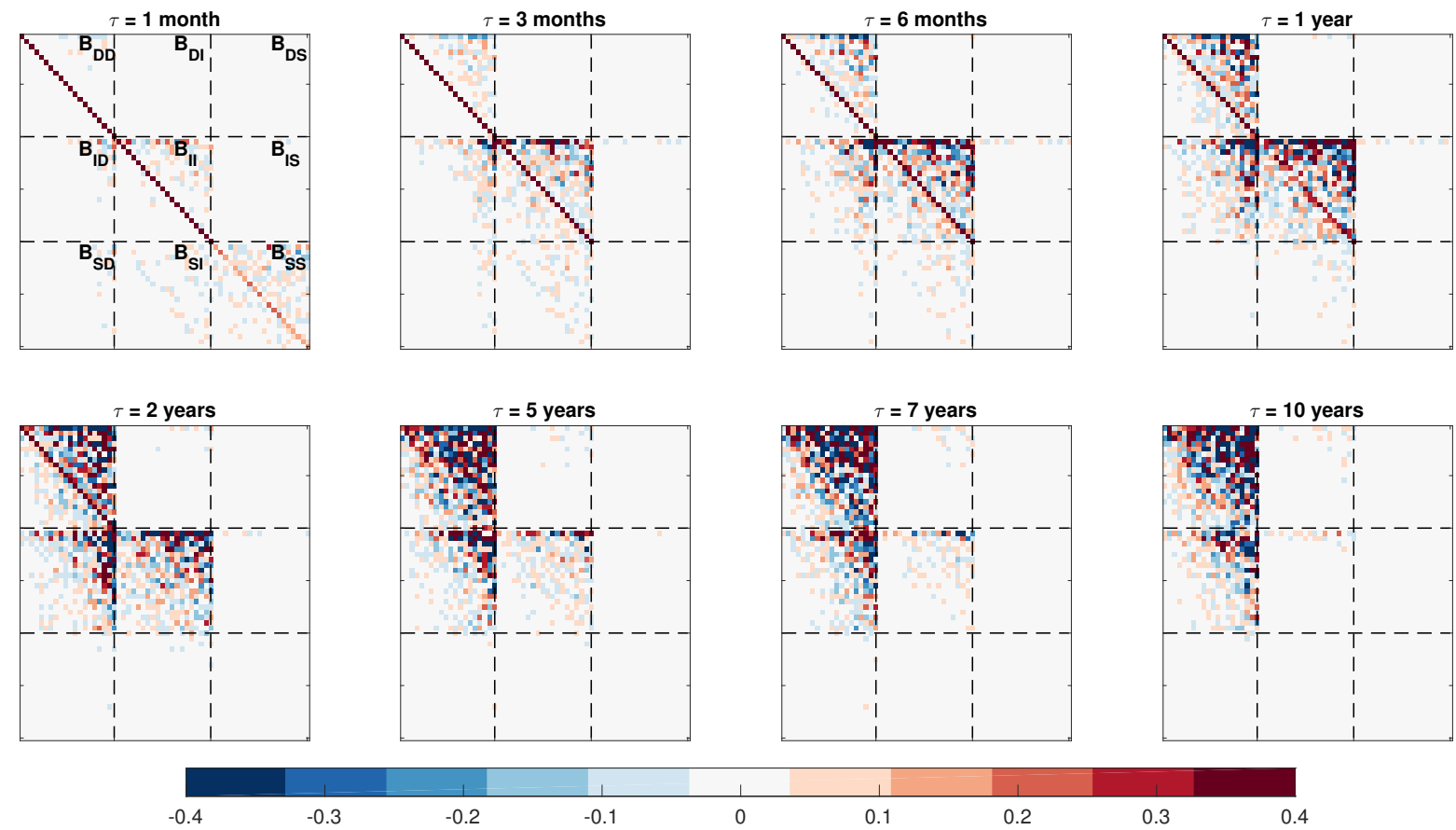

FIG. 10. Propagator matrices constructed from the 20 lead EOFs of each time scale using data from the whole domain (PA), at various lead times. The dotted lines indicated are the boundaries for the submatrices of the interactions between each time scale. $\boldsymbol{B}_{D D}, \boldsymbol{B}_{I I}$ and $\boldsymbol{B}_{I I}$ represent the interaction between each time scale with itself; $\boldsymbol{B}_{D I}$ and $\boldsymbol{B}_{D S}$ represent the decadal downscale interactions (decadal modes driving interannual and seasonal modes); $\boldsymbol{B}_{I S}$ represents the interannual downscale interaction (interannual modes driving seasonal modes); $\boldsymbol{B}_{I D}$ represents the interannual upscale interactions (interannual modes driving decadal modes); and $\boldsymbol{B}_{S D}$ and $\boldsymbol{B}_{S I}$ represent the seasonal upscale interactions (seasonal modes driving interannual and decadal modes). 